\title{
The use of multi criteria analysis to compare the operating scenarios of the hybrid generation system of wind turbines, photovoltaic modules and a fuel cell
}

\author{
Bartosz Ceran ${ }^{1, *}$ \\ ${ }^{1}$ Poznań University of Technology, Faculty of Electrical Engineering, Institute of Electrical Power \\ Engineering, Poland
}

\begin{abstract}
The paper presents the results of the use of multi-criteria analysis to compare hybrid power generation system collaboration scenarios (HSW) consisting of wind turbines, solar panels and energy storage electrolyzer - PEM type fuel cell with electricity system. The following scenarios were examined: the base S-I- hybrid system powers the off-grid mode receiver, S-II, S-III, S-IV scenarios -electricity system covers $25 \%, 50 \%, 75 \%$ of energy demand by the recipient. The effect of weights of the above-mentioned criteria on the final result of the multi-criteria analysis was examined.
\end{abstract}

\section{Introduction}

Fully distributed generation is playing an increasingly important role in the power system, especially wind and photovoltaic plants. While observing an increasing saturation of a power system by this type of sources, it is extremely important to gain knowledge about planning of the burden between unconventional and conventional sources based on carbon, which will continue to be the primary energy source in the coming years.

While planning collaboration between renewable sources with conventional ones, energy aspects of examined electricity generation technologies should be considered (efficiency process of processing of primary energy into electricity), economic aspects (cost of generating electricity) and environmental aspects (exhaust fumes emissions) [1].

The paper proposed the use of method of "programming compromise" to conduct a multi-criteria analysis [2, 3], aimed at selecting the best variant of the load distribution between the hybrid power generation system consisting of wind turbines, photovoltaic modules and energy storage electrolyzer - fuel cell and the electricity power system including the above mentioned aspects.

\footnotetext{
* Corresponding author: bartosz.ceran@put.poznan.pl
} 


\section{The analyzed hybrid power generation system}

Scheme of the analyzed receiver supply system is shown in Figure 1 [4, 5]. The excess energy produced from renewable sources is used for electrolysis process (decomposition of water into hydrogen and oxygen). Hydrogen is compressed and stored, and then used in a fuel cell to produce electricity, at a time when it is needed by customer.

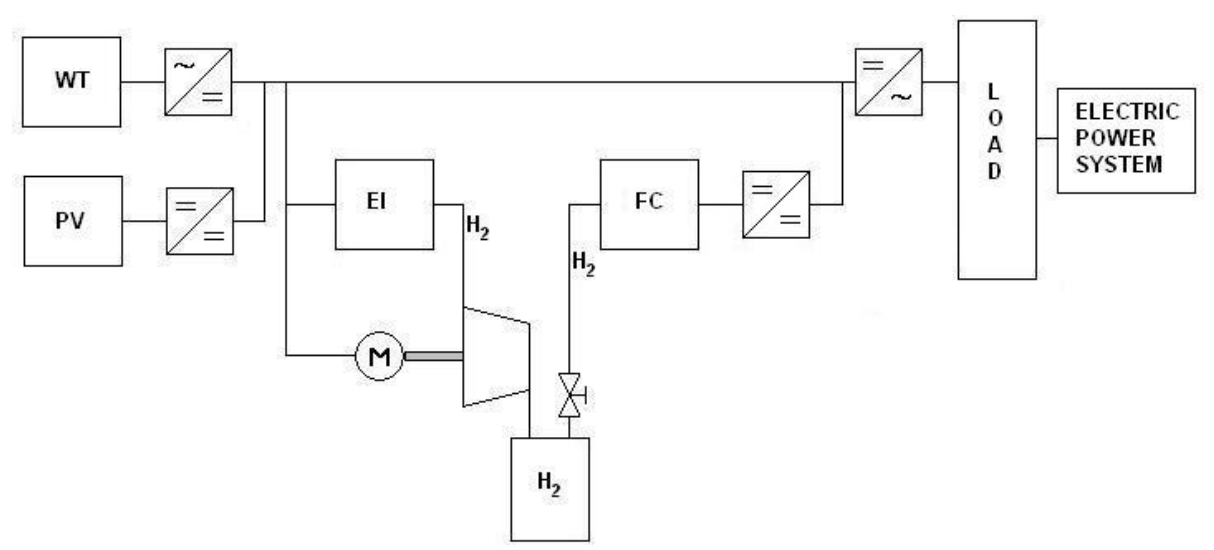

Fig. 1. Flowchart-hybrid power generation system.

The balance of power in the system, depends on the ratio of power generated by RES sources to the demand of the recipient. In the case where the demand is less than the power generated balance sheet equation takes the form [6].

$$
P_{\text {load }}=P_{P V}+P_{W T}-P_{\text {elek }}-P_{\text {comp }}+P_{\text {sys }}
$$

where: $P_{\text {load }}$ - power consumed by the recipient, $P_{P V}$ - power generated by the photovoltaic installation, $\mathrm{P}_{W T}$ - power generated by the wind plants, $P_{\text {elek }}-$ power consumed by electrolyzer, $P_{\text {comp }}-$ power consumed to drive the compressor, $P_{s y s}-$ power drawn from the power system.

If the demand exceeds the power produced by sources the receiver power describes the formula:

$$
P_{\text {load }}=P_{P V}+P_{W T}+P_{F C}+P_{s y s}
$$

where: $P_{F C}$ - power generated by the fuel cell stack.

\section{Scenarios of cooperation and decision-making criteria}

For the analysis were adopted two customer profiles shown in figures 2 and 3 with the marked scenarios of load distribution between the hybrid power generation system and electric power system. The base scenario S-I is a power of the receiver by hybrid power generation system in off-grid mode, without the electric power system. Another scenarios S-II, S-III, S-IV include covering parts of the load by the system in the following order: $25 \%, 50 \%$ and $75 \%$ of energy demand is covered by the electric power system. 


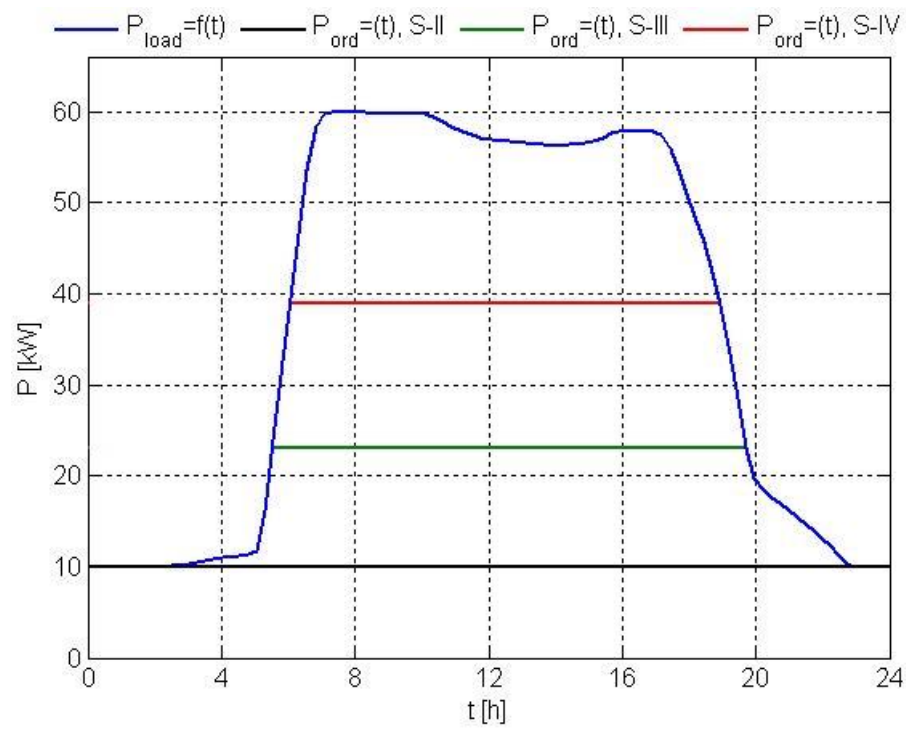

Fig. 2. Energy profile of the recipient 1 - work scenarios.

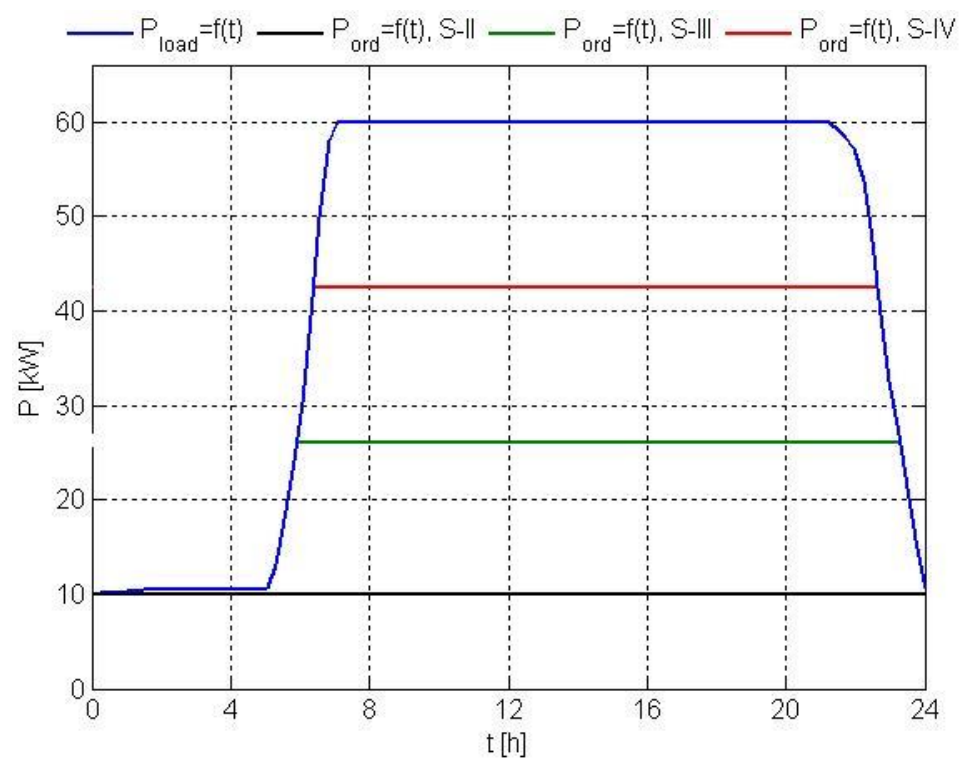

Fig. 3. Energy profile of the recipient 2 - work scenarios.

For each cooperation scenario a set of devices has been chosen (table 1) of the hybrid power system based on the energy analysis described in the paper [7]. 
Table 1. Equipment forming a hybrid power system for scenarios S-I...S-IV.

\begin{tabular}{|c|c|c|c|c|c|c|c|c|}
\hline & \multicolumn{7}{|c|}{ Profile 1 } & \multicolumn{5}{c|}{ Profile 2 } \\
\hline $\begin{array}{c}\text { Devices in hybrid } \\
\text { system }\end{array}$ & S-I & S-II & S-III & S-IV & S-I & S-II & S-III & S-IV \\
\hline Wind turbines [kW] & $3 \times 50$ & $2 \times 50$ & $2 \times 50$ & 50 & $4 \times 50$ & $3 \times 50$ & $2 \times 50$ & 50 \\
\hline $\begin{array}{c}\text { Panels PV-250 } \\
{[W p]}\end{array}$ & $380 \times 250$ & $325 \times 250$ & $52 \times 250$ & $31 \times 250$ & $373 \times 250$ & $318 \times 250$ & $197 \times 250$ & $97 \times 250$ \\
\hline Fuel cell [kW] & 50 & 50 & 40 & 20 & 50 & 50 & 40 & 20 \\
\hline Electrolyzer [kW] & 150 & 110 & 100 & 50 & 200 & 150 & 100 & 50 \\
\hline
\end{tabular}

As the decision criteria for the multi-criteria analysis the following indicators has been adopted:

$k_{1}$ - unit usage of additional hydrogen by the hybrid system,

$k_{2}$ - unit cost of energy production by the hybrid system,

$k_{3}$ - the indicator of carbon dioxide emission by hybrid power system and electric power system,

$k_{4}$ - the capacity of utilization of power ordered from the electric power system.

$$
k_{1}=\frac{M_{H_{2}}}{E_{\text {load }}}\left[\frac{k_{H_{2}}}{k W h}\right]
$$

where: $M_{H 2}$ - the amount of utilized additional hydrogen for backup purpose, $E_{\text {load }}$ - the demand for energy by the recipient.

$$
k_{2}=\frac{K_{e}}{E_{H P G S}}\left[\frac{P L N}{k W h}\right]
$$

where: $K_{e}$ - operating costs of hybrid system, $E_{H P G S}$ - the amount of energy produced by hybrid power generation system

In the case of $\mathrm{S} 1$ scenario, the cost of $1 \mathrm{kWh}$ generation in a hybrid system is almost twice bigger than an average energy cost charged by public consumers, which is rated at $0.56 \mathrm{PLN} / \mathrm{kWh}$. This high price is associated with high depreciation costs, which are assumed at the level of $10 \%$ of investment expenditure. As far as this instance is concerned, taking into consideration current prices of fuel cells, an investment expenditure of hybrid system, depending on particular scenario, is rated between 1.5 million and 3 million PLN.

$$
k_{3}=\frac{E_{\text {sys }} \cdot \mathrm{WE}_{\mathrm{CO}_{2}}+\mathrm{M}_{\mathrm{H}_{2}} \cdot \mathrm{CO}_{2} / \mathrm{H}_{2}}{E_{\text {load }}}\left[\frac{\mathrm{kg}_{\mathrm{CO}_{2}}}{\mathrm{kWh}}\right]
$$

where: $E_{s y s}$-energy input from the electricity system, $W E_{C O 2}$ - indicator of carbon dioxide emission in electricity system, $\mathrm{CO}_{2} / \mathrm{H}_{2}-$ the amount of carbon dioxide formed in the production of $1 \mathrm{~kg}$ of hydrogen in the steam reforming process of hydrocarbons

$$
k_{4}=\frac{E_{\text {sys }}}{P_{\text {ord }} \cdot t}\left[\frac{k W h}{k W h}\right]
$$

where: $P_{\text {ord }}$ - power ordered from the electric power system 


\section{Comparing the scenarios of work using multi-criteria analysis}

Multi-criteria analysis is a mathematical method which allows to select the most favorable solution, the so-called. scenario, in the light of adopted criteria. One of the methods of multi-criteria analysis is a method of "compromise programming" which ranks considered scenarios by distance from the so-called target point X (ideal point).

A mathematical record of distance measure of considered variant from the ideal point describes the formula:

$$
L_{\alpha}\left(S_{n}\right)=\sum_{m=1}^{M} w_{m}^{\alpha}\left(x_{m}^{\prime}-x_{n m}^{\prime}\right)^{\alpha}
$$

where: $L_{\alpha}$ - a measure of divergence of considered scenario $\mathrm{S}_{\mathrm{n}}$ from the ideal point, $\mathrm{w}_{\mathrm{m}}-$ weight factor $\mathrm{m}$ of this criterion, $\alpha$ - exponent measuring the deviation strategy from the ideal point, $x_{m}$ '- $m$ th coordinate of the ideal point, $x_{n m}{ }^{\prime}$ - normalized value of the evaluation criterion.

The most favorable scenario in the light of the adopted criteria complies with the relation:

$$
S_{j}=S^{*} \Leftrightarrow L_{\alpha}\left(S_{j}\right)=\min L_{\alpha}\left(S_{n}\right), \text { dla } \quad \mathrm{n}=1,2 \ldots . \mathrm{N} ; \alpha=1,2 \ldots \infty
$$

where: $S^{*}$ - selected scenario.

Comparison of the best scenario in the light of the adopted criteria with the other scenarios is accomplished through the threshold of acceptability PA defined as:

$$
P A=\frac{p}{100} \cdot \min L_{\alpha}\left(S_{n}\right)
$$

where: $p$ - a percentage value of the distance of the best scenario from the ideal point.

Acceptable scenarios meet the inequality:

$$
L_{\alpha}\left(S_{n}\right)-\min L_{\alpha}\left(S_{n}\right)<P A
$$

Mathematical notation of multi-criteria decision-making problem consisting of four scenarios $\mathrm{S}$ (I-IV), examined using four criteria $\mathrm{k}_{1}-\mathrm{k}_{4}$ represents a decision matrix called the matrix of payments (Table 2):

Table 2. Payment matrix of decision problem for scenarios S-I...S-IV.

\begin{tabular}{|c|c|c|c|c|c|c|c|c|}
\hline & \multicolumn{6}{|c|}{ Load scenarios of the power system } \\
\hline & \multicolumn{3}{|c|}{ Profile 1 } & \multicolumn{5}{c|}{ Profile 2 } \\
\hline Decision criteria & S-I & S-II & S-III & S-IV & S-I & S-II & S-III & S-IV \\
\hline $\mathrm{k}_{1}\left[\mathrm{kgH}_{2} / \mathrm{kWh}\right]$ & 0.233 & 0.163 & 0.104 & 0 & 0.259 & 0.197 & 0.089 & 0 \\
\hline $\mathrm{k}_{2}[\mathrm{PLN} / \mathrm{kWh}]$ & 1.15 & 1.32 & 1.33 & 1.51 & 1.08 & 1.18 & 1.22 & 1.36 \\
\hline $\mathrm{k}_{3}[\mathrm{kgCO} / \mathrm{kWh}]$ & 0.28 & 0.43 & 0.55 & 0.62 & 0.32 & 0.43 & 0.52 & 0.62 \\
\hline $\mathrm{k}_{4}[\mathrm{kWh} / \mathrm{kWh}]$ & 0 & 1 & 0.8 & 0.7 & 0 & 1 & 0.85 & 0.79 \\
\hline
\end{tabular}


Table 3. The normalized payment matrix for the scenarios S-I...S-IV.

\begin{tabular}{|c|c|c|c|c|c|c|c|c|}
\hline & \multicolumn{7}{|c|}{ Load scenarios of the power system } \\
\hline & \multicolumn{5}{|c|}{ Profile 1 } & \multicolumn{5}{c|}{ Profile 2 } \\
\hline $\begin{array}{c}\text { Normalized } \\
\text { decision criteria }\end{array}$ & S-I & S-II & S-III & $\begin{array}{c}\text { S- } \\
\text { IV }\end{array}$ & S-I & S-II & S-III & S-IV \\
\hline $\mathrm{k}_{1}(\min )$ & 0.00 & 0.30 & 0.55 & 1.00 & 0.00 & 0.30 & 0.55 & 1.00 \\
\hline $\mathrm{k}_{2}(\min )$ & 1.00 & 0.53 & 0.50 & 0.00 & 1.00 & 0.53 & 0.50 & 0.00 \\
\hline $\mathrm{k}_{3}(\min )$ & 1.00 & 0.58 & 0.22 & 0.00 & 1.00 & 0.58 & 0.22 & 0.00 \\
\hline $\mathrm{k}_{4}(\max )$ & 0.00 & 1.00 & 0.80 & 0.70 & 0.00 & 1.00 & 0.80 & 0.70 \\
\hline
\end{tabular}

\section{The results of multi-criteria analysis}

Studying the impact of weights of decision criteria on the outcome of multi-criteria analysis was started with the variant in which all the criteria were assigned the same value of the weight wm. Next the prevailing effect of one of the criteria was tested in relation to the others and its effect on the results of multi-criteria analysis using the following assumptions: prevalence of one criterion took place till the moment when as a result of multi-criteria analysis was indicated a favoured scenario by this criterion.

The degree of acceptability $\mathrm{p}$ adopted at a low level equal to 5\%. Due to this another scenarios were taken into account which were in the distance no more than $0.05 * \operatorname{minL} \alpha(\mathrm{Sn})$ from the best solution. The analysis was conducted for two criterion of aggregating value $\alpha$ equal to 1 and 2 . The scenarios are in order from most to least favorable. Acceptable variations are indicated with *. Multi-criteria analysis results are shown in Tables 4, 5 and Figures 4, 5 .

Table 4. Multi - criteria analysis results - profile 1.

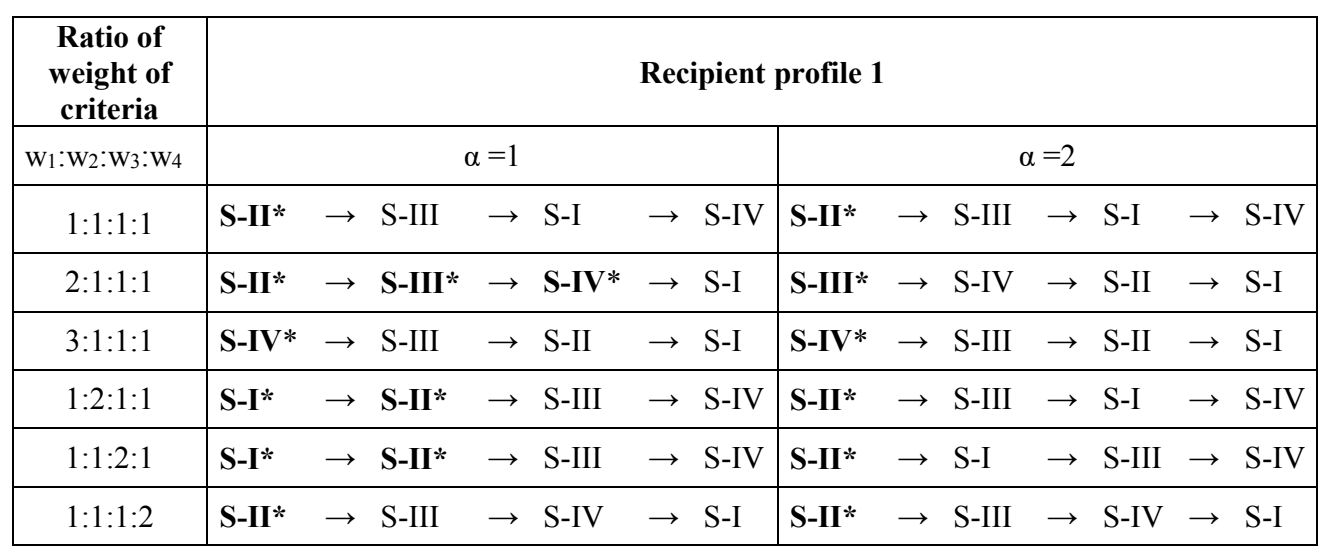


Table 5. Multi - criteria analysis results - profile 2.

\begin{tabular}{|c|c|c|c|c|c|c|c|c|c|c|c|c|}
\hline \multirow{2}{*}{\begin{tabular}{|c|}
$\begin{array}{c}\text { Ratio of } \\
\text { weight of } \\
\text { criteria }\end{array}$ \\
$\mathrm{w}_{1}: \mathrm{w}_{2}: \mathrm{w}_{3}: \mathrm{w}_{4}$ \\
\end{tabular}} & \multicolumn{12}{|c|}{ Recipient profile 2} \\
\hline & \multicolumn{6}{|c|}{$\alpha=1$} & \multicolumn{6}{|c|}{$\alpha=2$} \\
\hline $1: 1: 1: 1$ & S-II* & - & S-III & $\rightarrow$ & S-I & $\rightarrow$ S-IV & S-III* & $\rightarrow$ & S-II* & $\rightarrow \quad \mathrm{S}-\mathrm{I}$ & $\rightarrow$ & S-IV \\
\hline $2: 1: 1: 1$ & S-III* & - & S-IV & $\rightarrow$ & S-II & $\rightarrow$ S-I & S-III* & & S-IV & $\rightarrow \quad$ S-II & $\rightarrow$ & S-I \\
\hline $3: 1: 1: 1$ & S-IV* & - & S-III* & $\rightarrow$ & S-II & $\rightarrow \quad$ S-I & S-III* & $\rightarrow$ & S-IV & $\rightarrow \quad$ S-II & $\rightarrow$ & S-I \\
\hline $1: 2: 1: 1$ & S-II* & - & S-I & $\rightarrow$ & S-III & $\rightarrow$ S-IV & S-II* & & S-I & $\rightarrow$ S-III & $\rightarrow$ & S-IV \\
\hline $1: 3: 1: 1$ & S-I* & - & S-II & & S-III & $\rightarrow$ S-IV & S-II* & & S-I* & $\rightarrow$ S-III & $\rightarrow s$ & S-IV \\
\hline $1: 1: 2: 1$ & S-II* & - & S-IV & & S-III & $\rightarrow$ S-IV & S-II* & & S-I & $\rightarrow \quad$ S-III & $\rightarrow s$ & S-IV \\
\hline $1: 1: 3: 1$ & S-I* & - & S-II & & S-III & $\rightarrow$ S-IV & S-II* & $\rightarrow$ & S-I* & $\rightarrow$ S-III & $\rightarrow$ & S-IV \\
\hline $1: 1: 1: 2$ & S-II* & 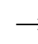 & S-III & & S-IV & $\rightarrow$ S-I & S-II* & $\rightarrow$ & SIII* & $\rightarrow \quad$ S-IV & $\rightarrow$ & S-I \\
\hline
\end{tabular}

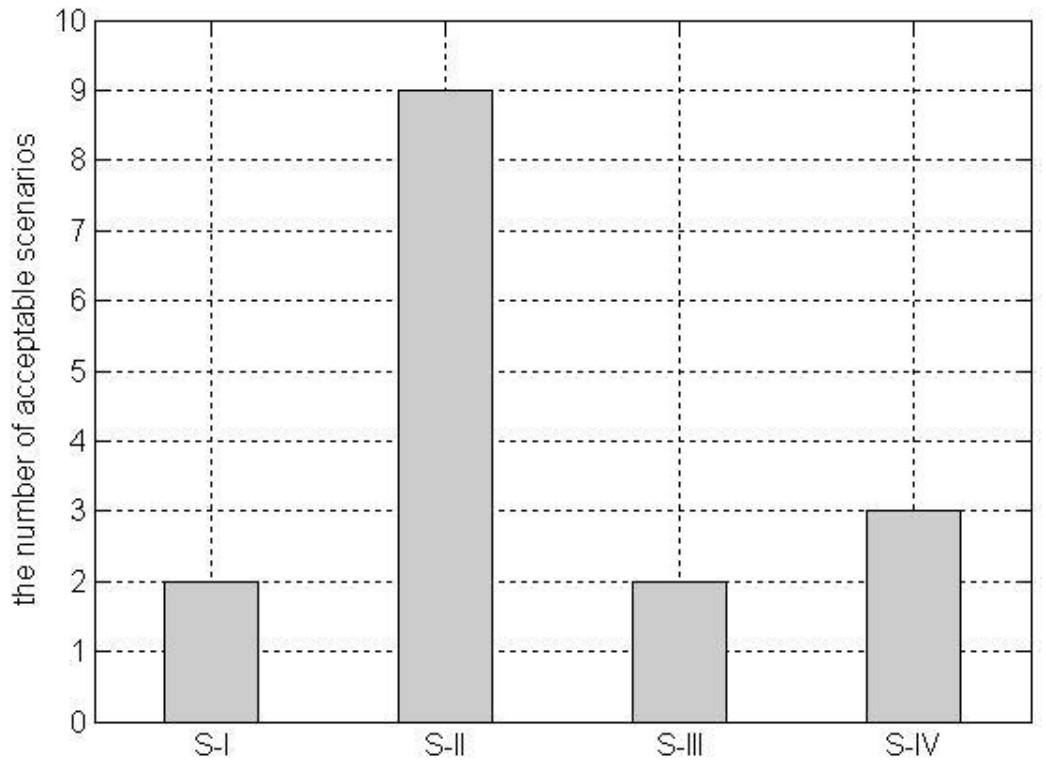

Fig. 4. Multi - criteria analysis results - profile 1 . 


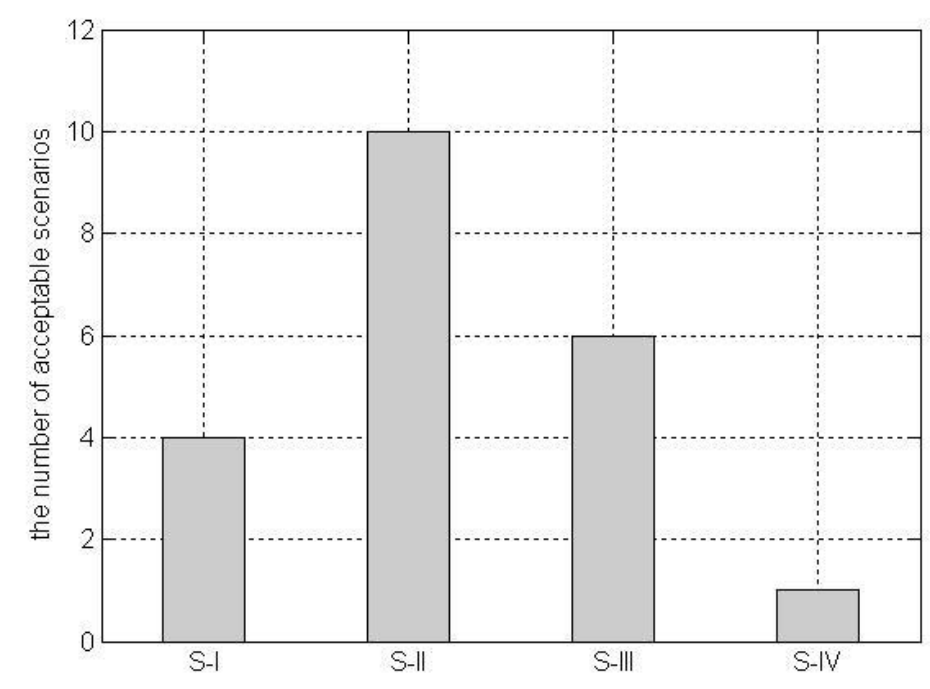

Fig. 5. Multi - criteria analysis results - profile 2.

\section{Conclusions}

The research allows to formulate the following conclusions:

- It is not possible to completely replace the classic power system with renew-able energy sources combined in hybrid power generation systems. The most frequently chosen scenario is S-II, where the electric power system covers the base load of the recipient.

- Planning the load distribution between the hybrid power generation system, consisting of wind turbines, solar panels and energy storage cell electrolyzer - fuel cell and the electric power system can be seen as the decision-making task that must be resolved according to various criteria (energy, economic, environmental) using multi-criteria, decision-making methods.

- The proposed analysis model can be a starting point for optimizing the operation of hybrid power systems based on sources of stochastic nature of work in the electric power system. It is possible to expand this model, e.g. by expanding by new decision criteria.

\section{Reference}

1. A. Nadimi, F. Adabi, IJRER 6, 2 (2016)

2. Z. Mucha, J. Mikosz, A. Generowicz, Environment Engineering 4, 145-155 (2012)

3. W. Wójcik, Z. Mucha, A. Generowicz, Acta Sci. Pol. 13, 3, 101-114 (2014)

4. B. Ceran, Q. Hassan., M. Jaszczur, K. Sroka, E3S Web Conf. 14, 01020 (2017)

5. R. Szczerbowski, B. Ceran, E3S Web Conf. 10, 00090, (2016)

6. C. Wang., M. H. Nehrir, IEEE Transactions 957-964, (2008)

7. B. Ceran, K. Sroka, Acta Energetica 23, 2, 36-42 (2015) 